\title{
Incidences and Occurences of Future Types of Victimization in Adolescents
}

\author{
Margareth Regina Gomes Veríssimo de Faria, Daniela Sacramento Zanini \\ Pontifical Catholic University of Goias, Goiânia, Brazil \\ Email: dazanini@yahoo.com
}

Received 10 July 2015; accepted 4 August 2015; published 7 August 2015

Copyright (C) 2015 by authors and Scientific Research Publishing Inc.

This work is licensed under the Creative Commons Attribution International License (CC BY). http://creativecommons.org/licenses/by/4.0/

(c) (i) Open Access

\begin{abstract}
This paper aimed to describe the differences between lifetime and past-year victimizations, to investigate the correlations between the victimizations in two different moments (lifetime and in the past year), and to investigate the influence of lifetime victimization on the occurrence of past-year victimization. Participants were 426 students, aged between 12 to 18 years, from primary and secondary public schools in Goiânia (Brazil). $54.2 \%(\mathrm{~N}=231)$ were female and $45.8 \%$ ( $\mathrm{N}$ $=195$ ) were male. The mean age of participants was 13.87 years $(S D=1.33$; Mean $=14$ years $)$. The results showed that lifetime victimizations tend to be higher than in the year before. The correlations between past-year and lifetime victimizations were significant and positive $(p<0.000)$, indicating that both follow the same direction, namely, increasing victimization at a given time coincides with increasing victimization at another time. It should also be noted that among all victimizations, peer victimization tends to achieve the highest probability of repetition $(61.8 \%)$, followed by sexual victimization $(55.6 \%)$, conventional crime $(47.4 \%)$, witnessing $(46.1 \%)$, and maltreatment $(45.5 \%)$. The positive correlations and regressions indicate positive relationships between the type of victimization, and lifetime occurrences influence past-year occurrences. Therefore, investigating past-year victimization can be considered a good predictor of the next-year occurrence of victimization.
\end{abstract}

\section{Keywords}

Victimization, Violence, Adolescents, Incidence, Reincidence

\section{Introduction}

The financial cost in Brazil for assisting victims of violence reaches 5\% of the gross domestic product. Among adolescents, mostvictims report cases of sexual (56\%), psychological (50\%) and physical (48\%) violence (Brazil, 2008). Most episodes (50\%) occur in their own homes and 38\% consist of repeat violence (Brazil, 2008). Re- 
garding the relationship with the abuser, $21 \%$ are unknown, $20 \%$ are friends or acquaintances, and $12 \%$ are the adolescents' own fathers (Brazil, 2008). Souza and Jorge (2006) state that the use of licit and illicit drugs and firearms collaborate with violence against children and adolescents, as they are the main factors involved in victimization and death. Many of adolescents' deaths in large Brazilian cities are due to conflicts that originated in gang fights in the retail drug market and account settlement or conflicts between the police and drug dealers.

In addition to the material cost, there is the psychological cost for those suffering from violence because, according to Finkelhor, Turner and Ormrod (2007), it is possible that a type of victimization can generate vulnerability to other types. Any form of violence is able to create psychological conditions that can increase the risk of different types of victimization in the future. On the other hand, the dissemination of victimization and the heterogeneity of the associations reinforce the feeling that this is a permanent condition for victims (Finkelhor, Ormrod \& Turner, 2007). Recent Brazilian studies also describe the consequences of long-term effects of victimization, in which victims had suggestive symptoms of post-traumatic stress disorder (Williams, D'Affonseca, Correia, \& Albuquerque, 2011).

Studies on victimization seek to describe five different types of violence against children and adolescents: conventional crime, maltreatment, victimization by peers, sexual victimization, witnessing and indirect victimization (Finkelhor, Hamby, Ormord, \& Turner, 2005). This instrument can cover all types of victimization described so far, even those in the intra-family context. For these studies the translated version adapted for the Brazilian population was used (Faria \& Zanini, 2011).

Analyzing the significant differences in lifetime and past-year victimizations helps understand the dynamics of victimizations and allows for an assessment of the probability of further occurrences along the adolescents' lives. In addition, early identification of victimizations for precise interventions becomes imperative, in order to stop the repeating cycle and the harmful effects of this exposure. Therefore, this article aims to determine the relationship between lifetime and past-year victimizations in a sample of adolescents, in order to foresee the influence of current victimizations on future victimization.

\section{Method}

\subsection{Participants}

Four hundred twenty-six individuals aged 12 to 18 years participated in the study; elementary and secondary students of four public schools in Goiânia (Brazil). State schools were chosen because the clientele in these institutions consists of adolescents. The schools were selected by conglomerates after agreeing to participate in the study, during a meeting to present its objectives.

Participants were excluded from the sample when they had any intellectual impairment that prevented understanding the instrument questions, or a visual impairment requiring teachers' help or support to answer, compromising the accuracy and confidentiality of information.

\subsection{Instruments}

The instrument used in this study was the version translated into Portuguese and adapted to the Brazilian population, Juvenile Victimization Questionnaire (JVQ) (Finkelhor, Hamby, Ormord, \& Turner, 2005). By using the 34-item questionnaire, it is possible to assess five types of victimization: conventional crime (items 1 to 8 ), maltreatment (items 9 to 12), victimization by peers (items 13 to 18), sexual victimization (items 19 to 25), witnessing and indirect victimization (items 26 to 34). Each item can be coded by 0 , if the students have not experience this victimization in the last year or in lifetime, or 1 , if the student have experienced this victimization in the last year or in lifetime and the final score for each type of victimization is obtained by adding the items.

\subsection{Procedures}

After approval of the project by the Ethics Committee and authorization from the State Department of Education of Goiás, the schools were contacted in order to explain the research objectives. Dates and times were scheduled with the schools that agreed to participate for clarification of the research objectives and handling of consent forms. The students were invited to participate on a voluntary basis, with the permission of their guardians, following guidelines and requirements of the Ethics Committee. For those who agreed to participate in the survey, the consent forms were provided for parents and guardians; the participants who returned them with their par- 
ents’ permission participated in data collection as previously scheduled.

\subsection{Data Analysis}

The collected data were analyzed using descriptive statistics, paired t-test, correlations and simple regressions in the Statistical Package for Social Sciences (SPSS) version 20.0.

\section{Results}

Of the 426 participants, $54.2 \%(\mathrm{~N}=231)$ were female and $45.8 \%(\mathrm{~N}=195)$ were male. The mean age of participants was 13.87 years $(\mathrm{SD}=1.33$; Mean $=14$ years $)$.

\subsection{Comparison between Lifetime and Past-Year Victimizations}

In order to investigate whether the differences between the lifetime and past-year victimization are really significant, a paired t-test was performed. The t-test of means between lifetime and past-year victimizations showed that victimizations tend to occur more frequently throughout their lives than in the past year, which is likely a result of victimization accumulation over the years.

However, regarding victimization by peers $(t=-2.470 ; p \leq 0.014)$ and sexual victimization $(t=-2.155 ; p \leq$ 0.032 ), the level of significance demonstrates that the scene tends to be the same, particularly for sexual victimization (Table 1), that is, they have similarly occurred during their lifetime and in the last year, because the level of significance of the differences between means decreases from $p<0.000$ to $p<0.05$, thereby showing that there tend to be smaller differences from one moment to the other.

Nevertheless, the results demonstrate that lifetime victimization tends to be higher than in the past year, a factor understood as arising from the accumulation of occurrences over one's lifetime compared to past year, which includes only twelve months.

\subsection{Correlations and Influences of Lifetime and Past-Year Victimizations}

The assessment of the occurrences of lifetime victimization and past-year victimization can indicate that there are relationships between the different types of victimization. Positive correlations between the victimizations indicate a directly proportional relationship between them at the different times.

The Pearson's correlation between past-year and lifetime victimizations aimed to investigate the relationship between these two moments. The results in Table 2 show that the correlations between past-year and lifetime victimizations are significant and positive $(p<0.000)$, indicating that victimizations in these two moments have increased or decreased together. The positive and significant correlations between past-year and lifetime victimizations also demonstrate that past-year victimizations have maintained a similar relationship with lifetime

Table 1. Means, standard deviations (in parentheses) and statistical test of lifetime and past-year victimizations.

\begin{tabular}{|c|c|c|c|c|c|c|c|}
\hline & & \multicolumn{3}{|c|}{ Performed measures } & \multicolumn{3}{|c|}{ Statistical test } \\
\hline & & Mean & $\mathrm{N}$ & SD & $t$ & Gl & $p$ \\
\hline \multirow{2}{*}{ Conventional crime } & Last year & 1.7697 & 304 & 1.63893 & \multirow{2}{*}{-10.272} & \multirow{2}{*}{303} & \multirow{2}{*}{0.000} \\
\hline & Lifetime & 2.5822 & 304 & 1.83291 & & & \\
\hline \multirow{2}{*}{ Maltreatment } & Last year & 1.2384 & 365 & 1.10227 & \multirow{2}{*}{-5.149} & \multirow{2}{*}{364} & \multirow{2}{*}{0.000} \\
\hline & Lifetime & 1.4932 & 365 & 1.22837 & & & \\
\hline \multirow{2}{*}{ Peer } & Last year & 1.2146 & 233 & 1.24095 & \multirow{2}{*}{-2.470} & \multirow{2}{*}{232} & \multirow{2}{*}{0.014} \\
\hline & Lifetime & 1.3476 & 233 & 1.27786 & & & \\
\hline \multirow{2}{*}{ Sexual } & Last year & 0.4972 & 362 & 0.97119 & \multirow{2}{*}{-2.155} & \multirow{2}{*}{361} & \multirow{2}{*}{0.032} \\
\hline & Lifetime & 0.5829 & 362 & 1.11650 & & & \\
\hline \multirow{2}{*}{ Witnessing or indirect } & Last year & 2.3302 & 321 & 1.83286 & \multirow{2}{*}{-6.311} & \multirow{2}{*}{320} & \multirow{2}{*}{0.000} \\
\hline & Lifetime & 2.8910 & 321 & 2.09999 & & & \\
\hline
\end{tabular}


Table 2. Correlations between past-year victimizations and lifetime victimizations.

\begin{tabular}{|c|c|c|}
\hline \multicolumn{2}{|c|}{ Types of victimization } & $\begin{array}{c}r \\
(p)\end{array}$ \\
\hline Conventional crime & $\begin{array}{l}\text { Past-year } \\
\text { Lifetime }\end{array}$ & $\begin{array}{c}0.690 \\
(0.000)\end{array}$ \\
\hline Maltreatment & $\begin{array}{l}\text { Past-year } \\
\text { Lifetime }\end{array}$ & $\begin{array}{c}0.676 \\
(0.000)\end{array}$ \\
\hline Peer & $\begin{array}{l}\text { Past-year } \\
\text { Lifetime }\end{array}$ & $\begin{array}{c}0.787 \\
(0.000)\end{array}$ \\
\hline Sexual & $\begin{array}{l}\text { Past-year } \\
\text { Lifetime }\end{array}$ & $\begin{array}{c}0.746 \\
(0.000)\end{array}$ \\
\hline Witnessing or indirect & $\begin{array}{l}\text { Past-year } \\
\text { Lifetime }\end{array}$ & $\begin{array}{c}0.680 \\
(0.000)\end{array}$ \\
\hline
\end{tabular}

victimization. In this case, when one of them increases, the other one tends to increase too.

A stronger correlation between past-year and lifetime victimizations was found, but positive correlations indicate that any kind of victimization is positively related with all its other forms.

These data are also important because they show significant results on the incidence and recurrence. In order to investigate whether lifetime victimizations can have influenced the occurrence of subsequent victimizations, and whether the current victimizations can predict others in the future, a simple regression was calculated for each moment.

The ANOVA test $(\mathrm{F}(1.302)=273.963)$ shows that the model is significant for victimizations by conventional crime because it is associated with a probability value in the order of $p<0.000$ (Table 3). The experiences of lifetime victimizations by conventional crime explain $47.4 \%$ of those occurring in the last year. Thus, lifetime victimization by conventional crime was an important factor for victimization by conventional crime in the past year.

With similar results, lifetime maltreatment explains past-year occurrences in $45.5 \%$ of victimizations ( $\mathrm{F}$ $(1.363)=305.230, p<0.000)$. Regarding victimizations by peers, stronger values are observed in the model: lifetime victimizations explain $61.8 \%$ of past-year victimizations $(\mathrm{F}(1.231)=376.450, p<0.000)$ (Table 3$)$. Lifetime sexual victimizations were also high, explaining $55.6 \%$ of past-year victimizations $(\mathrm{F}(1.360)=$ 452.212, $p<0.000$ ) (Table 3). We can state that the experience of lifetime victimization favored current victimizations and that current victimizations will favor future victimizations. Still, lifetime indirect or witnessed victimizations explain $46.1 \%$ of past-year victimizations $(\mathrm{F}(1.319)=274.402, p<0.000)$ (Table 3$)$.

Of all victimizations, victimization by peers tends to be those most likely repeatable, followed by sexual victimization, victimization by conventional crime, witnessed victimization and maltreatment.

\section{Discussion}

This article aimed to describe the differences between past-year and lifetime victimizations; to investigate the correlations between victimizations in two different moments (lifetime and in the past year), and to investigate the influence of lifetime victimization on the occurrence of past-year victimization.

The mean number of victimizations was higher in the lifetime compared with the past year, which can be explained by the longer time of assessment and hence the accumulation of victimization. However, victimization by peers and sexual victimization tend to have less significant differences when both moments are compared, thereby suggesting that the occurrence of these two types of victimization might have increased in the last year.

Lifetime victimization by peers and sexual victimization (Table 3) explained the occurrence of past-year in $61.93 \%$ of victimizations by peers and in $55.65 \%$ of sexual victimizations. As also demonstrated by the correlations (Table 2), a positive correlation among all types of victimization indicates that one victimization increases the risk of other occurrences in adolescents. If any of them increases the chances of occurrence of other types of victimization, then these two types can be considered the most worrying because they have higher values of 
Table 3. Victimization by conventional crime, maltreatment, victimization by peers, sexual victimization, witnessing and indirect victimization-results from the simple regression, using as a dependent variable the criterion last year and as an antecedent variable the criterion lifetime.

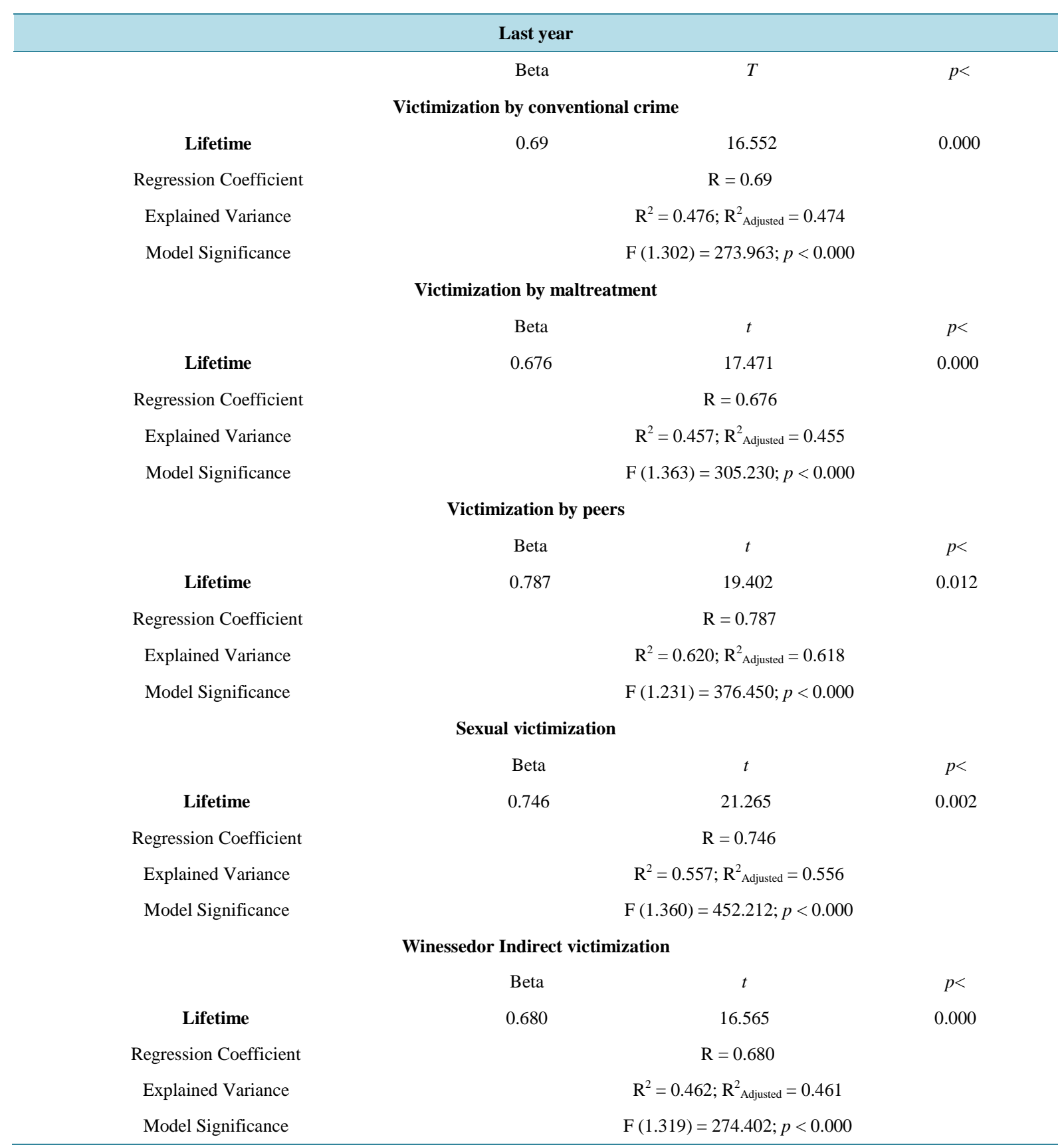

explained variance from lifetime to past-year victimizations. Therefore, they pose more risk for adolescents to experience any other type of victimization, including the same type.

In other words, these results show that lifetime victimization has influenced the past-year victimizations. This means that the continuity of current victimization experiences can favor the experience of future victimizations, since they are related. Therefore, investigating past-year victimizations can be considered a good predictor of events in the coming years. In addition, victimization by peers and sexual victimizations were more likely to repeat, and considering that any type of victimization sets a precedent for others, it is important to care for and prevent any kind of victimization, especially those that are most likely to relapse. 
One explanation for these results can lie in the theories on learned helplessness that explain the difficulty that individuals have in responding appropriately to traumatic events over which they believe they have no control (Seligman, 1975, 1991, cited by Myers, 2014). The repeated victimizations can be considered traumas, confirming the victim's idea that it is not possible to have control over the situation and that he is doomed to suffer. For Bandura (1994), self-efficacy influences how people think, feel and act. Self-efficacy is the judgment that people have of their abilities to solve problems or achieve their goals. Self-efficacy helps the individual determine what to do using their skills and abilities. People with low self-efficacy perceive problem situations as more difficult than they really are and feel unable, because they attribute the failures to personal aspects and lose faith in themselves (Bandura, 1994).

Whereas any type of victimization sets a precedent for the others, it is important to care for and prevent any kind of victimization, especially those with greater probability of recurrence, because they can cause the feeling of lack of control and make victims more passive regarding the recurrences.

Despite of this discussion data from this study should be analised with caution because it is based on self-report questionnaire and a transversal study and could be affected by the effect of participant's memory and emotions. Future studies should focused on multiple methodologies to solve or investigate the effect of self-report and memory aspects.

\section{References}

Bandura, A. (1994). Self-Efficacy. In V. S. Ramachaudran (Ed.), Encyclopedia of Human Behavior (Vol. 4, pp. 71-81). New York: Academic Press. (Reprinted in H. Friedman (Ed.) (1998). Encyclopediaof Mental Health. San Diego: Academic Press).

Brazil (2008). Ministério da Saúde. Temático Prevenção de Violência e Cultura de Paz III. Brasília: Organização PanAmericana da Saúde. Painel de Indicadores do SUS, 5.

Faria, M. R. G. V. \& Zanini, D. S. (2011). Análise da Compreensão dos Itens do Questionário de Vitimização (JVQ) após Tradução para o Português. Trabalho apresentado como Pôster na 63a Reunião Anual da SBPC, 10 a 15 de julho de 2011UFG-Goiânia, Go. http://www.sbpcnet.org.br/livro/63ra/resumos/resumos/6155.htm

Finkelhor, D., Ormrod, R. K., \& Turner, H. A. (2007). Re-Victimization Patterns in a National Longitudinal Sample of Children and Youth. Child Abuse \& Neglect, 31, 479-502. http://dx.doi.org/10.1016/j.chiabu.2006.03.012

Finkelhor, D., Ormrod, R., Turner, H., \& Hamby, S. L. (2005). The Victimization of Children and Youth: A Comprehensive. National Survey. Child Maltreatment, 10, 5-25. http://dx.doi.org/10.1177/1077559504271287

Myers, D. G. (2014). Psicologia Social (10ª ed.). Porto Alegre: AMGH.

Souza, E. R., \& Jorge, M. H. P. de M. (2006). Impacto da violência na infância e adolescência brasileiras: Magnitude da morbimortalidade. Em: Lima, C. A. de et al. (Org.). Violência faz mal à saúde. Brasília: Ministério da Saúde. (Série B. Textos Básicos de Saúde).

Williams, L. C. A., D’Affonseca, S. M., Correia, T. A., \& Albuquerque, P. P. (2011). Efeitos a longo prazo da vitimização escolar. Gerais: Revista Interinstitucional de Psicologia, 4, 187-199. 